\title{
Effect of Pavement Thickness and Width on Liquefaction- Induced Settlements and the Contribution of Sand Ejecta in Total Settlement
}

\author{
Muhammad Mohsan (D) Takashi Kiyota - Muhammad Umar · Toshihiko Katagiri
}

Received: 7 February 2020/ Accepted: 14 March 2021 / Published online: 15 April 2021

(C) The Author(s) 2021

\begin{abstract}
This paper investigates the settlement in a pavement due to soil liquefaction. Four 1-g shaking table tests were performed on saturated sand bedpavement model to understand the factors affecting the liquefaction-induced settlements and their relation to the pavement thickness and width. All the tests were performed with a base acceleration of 320 gal in a laminar box. The shaking table tests revealed that the total settlement reduced with the increase in the pavement thickness. The pavement with the same thickness but different width showed that the total settlement reduced with the increase in the pavement width. The co-seismic settlement and post-seismic settlement depend upon the thickness and width of the pavement, and the maximum contribution of the sand ejecta is around $7.7 \%$ in the total settlement.
\end{abstract}

Keywords Pavement - Shaking table test . Liquefaction $\cdot$ Settlement $\cdot$ Sand ejecta

\footnotetext{
Muhammad Mohsan is doing PhD at TU Delft now. These research experiments were conducted at the University of Tokyo during his master degree.
}

M. Mohsan $(\bowtie) \cdot$ T. Kiyota $\cdot$ M. Umar $\cdot$ T. Katagiri Institute of Industrial Science, University of Tokyo, 4-6-1 Komaba, Meguro-ku, Tokyo 153-8505, Japan

e-mail: M.Mohsan@tudelft.nl

M. Mohsan

Civil Engineering \& Geosciences, TU Delft, Stevinweg 1, 2628 CN Delft, Netherlands

\section{Introduction}

Soil liquefaction-induced settlement has caused severe damages to buildings and roads in the Tokyo Bay area during the 2011 off Pacific coast of Tohoku Earthquake, Japan. Konagai et al. (2013) conducted a Light Detection and Ranging (LIDAR) survey to collect the elevation data before and after the 2011 earthquake, and prepared a liquefaction-induced subsidence map of the west part of the Tokyo Bay area by comparing the Digital Surface Models (DSMs). They observed that the ground subsidence was concentrated more along the residential roads compared to structural roads designed for heavy traffic. Suyama et al. (2016) reported similar observations by extracting road subsidence of around 224 points in the Tokyo Bay area after the earthquake. Also, Kajihara et al. (2015) showed that under the same liquefaction potential, liquefaction-induced settlement in structural roads was significantly less in contrast to ordinarytype roads in residential areas.

Settlement in roads can cause significant disruption to road traffic after an earthquake. Considering this, Kajihara et al. (2020) prepared a hazard map translating the effect of road pavement thickness in the road network in Urayasu city for emergency vehicle and evacuation activities after the occurrence of liquefaction. The observations reported by Kajihara et al. (2015) and Suyama et al. (2016) suggest that the liquefaction-induced settlement is affected by the 
dimension of pavement structure (thickness and width). Therefore, the aim of this research is to provide experimental evidence and mechanism associated with the effect of pavement structure on the liquefaction-induced settlement of sandy soil. In addition to that, observation of sand ejecta and its contribution to the total settlement is also discussed in this study.

Large soil specimen placed on a shaking table can better simulate the seismic ground shaking under 1-g or centrifugal conditions (De Alba et al. 1976; Van Laak et al. 1994). Recent studies via shaking table model test have been mainly focused on understanding liquefaction-induced mechanisms related to soil-structure foundation interaction (Motamed et al. 2010; Dashti et al. 2010) or mitigation measures (Rasouli et al. 2012; Kheradi et al. 2018). These studies reported that the resistance to excess pore pressure generation and settlement depends on the characteristics of the overlaying structure and seismic motion. Also, the soil-structure interaction can affect the permanent deformation in the ground.

Total settlement following liquefaction is the sum of shear-induced deformation (Fig. 1a and b), volume contraction-induced deformation (Fig. 1c and d), and soil loss due to ejecta (Fig. 1e). Although many researchers have shown interpretation of shear-induced and volume contraction-induced deformations due to liquefaction, a part of the settlements due to sand ejecta is still missing in the literature. Despite their observation in the field, sand boiling is unnoticeable in laboratory testing. Miles et al. (2018) conducted free field rigid model shaking table tests and concluded that fines content is key to whether or not sand boils form, and the sand ejecta was unobserved in uniform sand.

Soil resistance against excess pore water pressure can be affected by fixed boundaries during shaking in a rigid model box. Thus, in this study, to address that, a laminar box with flexible boundaries is employed to reproduce layer ground shaking. A pavement with different combinations of width and thickness is prepared and subsequently subjected to shaking. The test results are compared in terms of rate of settlement and their relation to excess pore water generation.

\section{Experimental Setup and Methodology}

\subsection{Shaking Table}

The tests reported in this study are performed using a 1-g shaking table at the Institute of Industrial Science, the University of Tokyo. The shaking table primarily consists of a hydraulic pump, actuator, and accelerometer to monitor the input acceleration. This is further connected to a data acquisition system, which consists of a signal amplifier, signal converter, control panel, and computer system to store the output data. All other specifications of the shaking table are provided in Table 1. The stress level in the 1-g shaking table is much lower as compared to actual prototype structure. (a)

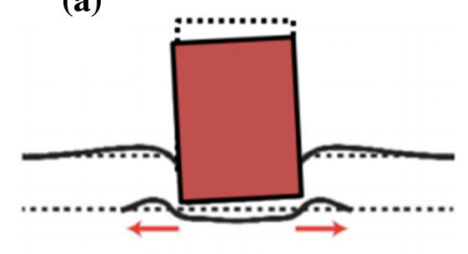

(c)

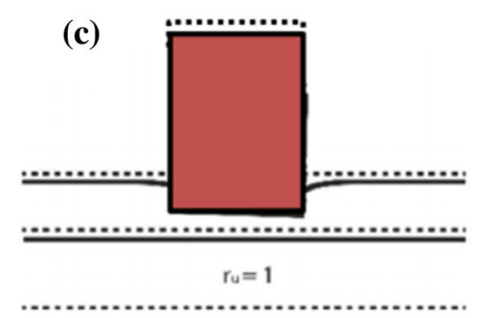

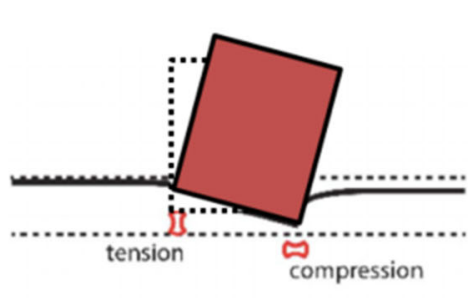

(d)

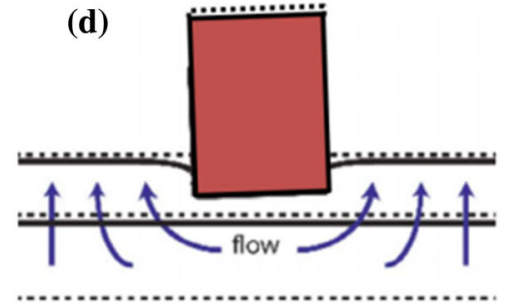

(b)

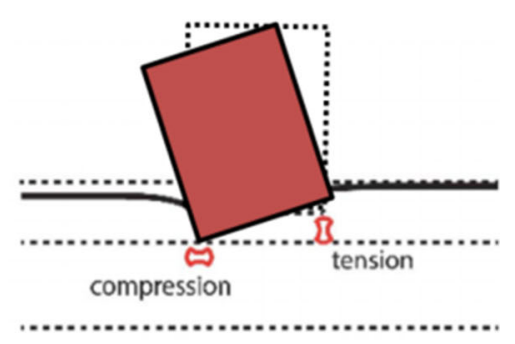

(e)

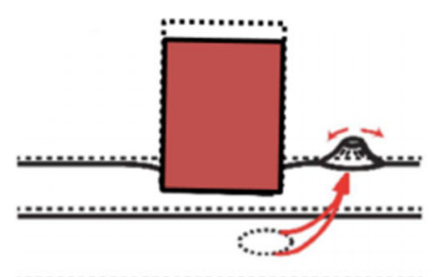

Fig. 1 Mechanism of liquefaction induced settlements (modified from Bray and Macedo (2017)) 
Table 1 Details of shaking table

\begin{tabular}{ll}
\hline Frequency range & DC-100 Hz \\
\hline Maximum loading weight & $2000 \mathrm{~kg}$ \\
Dimensions & $1.50 \mathrm{~m} \times 1.50 \mathrm{~m}$ \\
Excitation force & Sine wave: $19.6 \mathrm{kN}$ (2000 kgf) \\
& Pulse wave: $29.4 \mathrm{kN}$ (3000 kgf) \\
Maximum displacement & $150 \mathrm{~mm}$ \\
Maximum speed & $1.1 \mathrm{~m} / \mathrm{s}$ \\
Maximum acceleration & $1000 \mathrm{gal}$ \\
\hline
\end{tabular}

Therefore, the tests are scaled down to $1 / 20$ scale according to the similitude laws proposed by Iai (1989) as shown in Table 2.

\subsection{Laminar Soil Container}

A laminar shear box was developed with a dimension of $1000 \times 400 \times 700 \mathrm{~mm}(\mathrm{~L} \times \mathrm{W} \times \mathrm{H})$ to serve as a soil container as shown in Fig. 2. A set of seventeen horizontal laminae are placed on each other inside the skeleton supported by linear bearings in such a way that the linear movement is allowed in the shaking direction. Each layer can move independently as shown in Fig. 3 to allow the box to provide flexible boundaries. The movement in the other direction is restricted through anti-shake bearings. One lamina consists of a hollow, high strength, lightweight aluminum box-section bolted together to make the horizontal assembly having the plan dimensions of $400 \times 1000 \mathrm{~mm}$. Each lamina is guided by four linear bearings that allow the movement in one direction.

A $2 \mathrm{~mm}$ water-tight, flexible rubber membrane is inserted inside the container. Before placing the soil in the container, a set of two box sections each of which is clamped on a shorter side of the container to prevent the movement during the sample preparation and removed before the application of seismic loading. Eleven porous stones are placed at the base of the

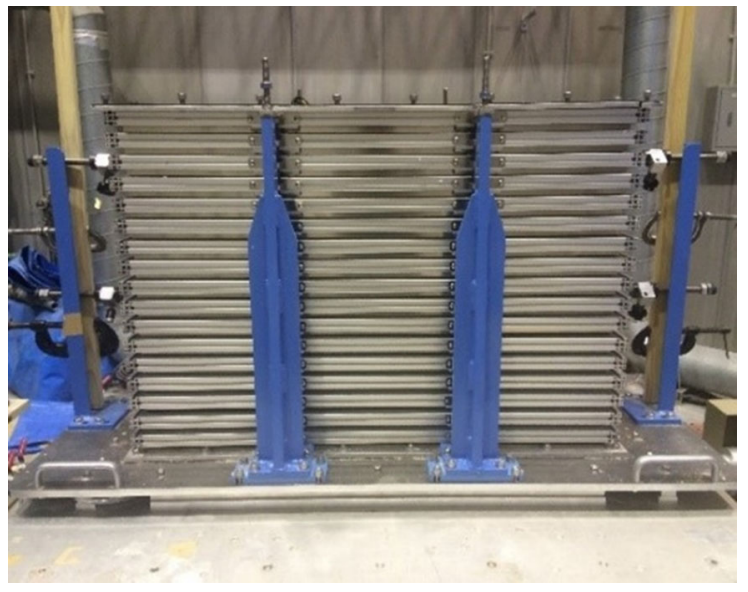

Fig. 2 Laminar soil box during sample preparation

laminar container that was used to inject/extract water for saturation/desaturation. A $15 \mathrm{~mm}$ solid steel base was attached to avoid the movement at soil-base plate interference. The effectiveness of the newly developed laminar box was studied by Mohsan et al. (2018), by comparing the shaking table test performed with a rigid soil box. They showed that the fixed boundaries delay the occurrence of liquefaction.

\subsection{Material, Sample Preparation and Input Motion}

A model ground was prepared with silica sand No. 5 and pavement was independently prepared by mixing silica sand No. 5, Kaolin clay, and ordinary Portland cement $(8: 2: 1)$. The list of tests performed with different pavement structure (thickness and width) are provided in Table 3 and the properties of silica sand No. 5 are listed in Table 4. The particle size distribution curve of silica sand is shown in Fig. 4.

The ground was prepared by water sedimentation to ensure a high degree of saturation. Firstly, the laminar container was filled with a water level up to $100 \mathrm{~mm}$. Subsequently, air-dried sand was dropped from a height of $600 \mathrm{~mm}$ above the water surface through a
Table 2 Scaling relationship for model testing

\begin{tabular}{lll}
\hline Properties of the model & Model/prototype & For N = 20 \\
\hline Pavement length/width/thickness & $1 / \mathrm{N}$ & $1 / 20$ \\
Relative density & - & $47-55 \%$ \\
Frequency & $1 / \mathrm{N}^{0.75}$ & $1 / 10$ \\
Acceleration & 1 & $320 \mathrm{gal}$ \\
\hline
\end{tabular}




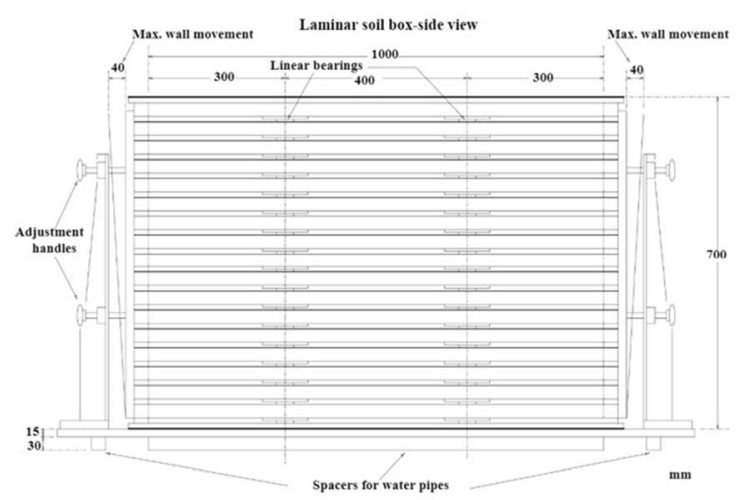

(a)

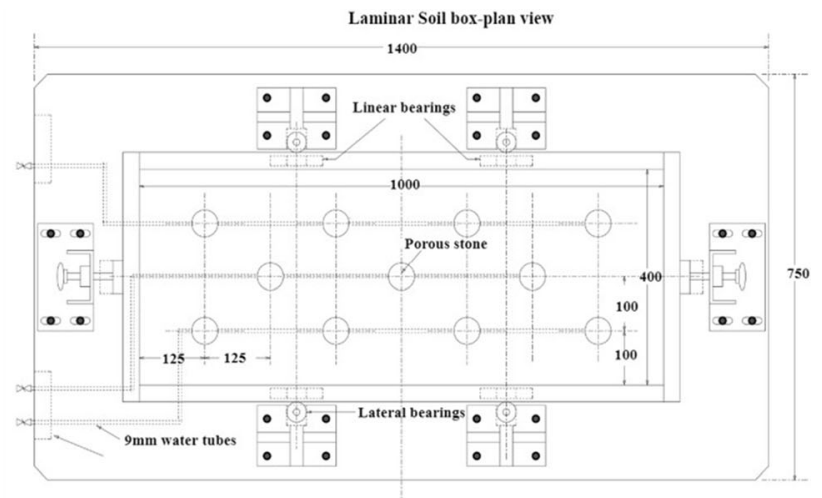

(b)

Fig. 3 Laminar box size configuration a side view $\mathbf{b}$ top view

Table 3 List of shaking table tests performed

\begin{tabular}{lllll}
\hline Case & $\begin{array}{l}\text { Pavement thickness }(\mathrm{h}- \\
\mathrm{mm})\end{array}$ & $\begin{array}{l}\text { Pavement width }(\mathrm{b}- \\
\mathrm{mm})\end{array}$ & $\begin{array}{l}\text { Pressure exerted by at the base of pavement } \\
(\mathrm{kPa})\end{array}$ & $\begin{array}{l}\text { Pavement weight } \\
(\mathrm{kN})\end{array}$ \\
\hline 1 & 30 & 600 & 0.63 & 0.15 \\
2 & 60 & 600 & 1.26 & 0.30 \\
3 & 90 & 600 & 1.89 & 0.45 \\
4 & 60 & 300 & 1.26 & 0.15 \\
\hline
\end{tabular}

Table 4 Properties of silica sand No. 5

\begin{tabular}{llllll}
\hline $\mathrm{D}_{50}$ & $\rho_{\min }$ & $\rho_{\max }$ & $\mathrm{Gs}$ & $e_{\min }$ & $e_{\max }$ \\
\hline $0.67 \mathrm{~mm}$ & $1.30 \mathrm{~g} / \mathrm{cm}^{3}$ & $1.58 \mathrm{~g} / \mathrm{cm}^{3}$ & 2.638 & 0.65 & 1.00 \\
\hline
\end{tabular}

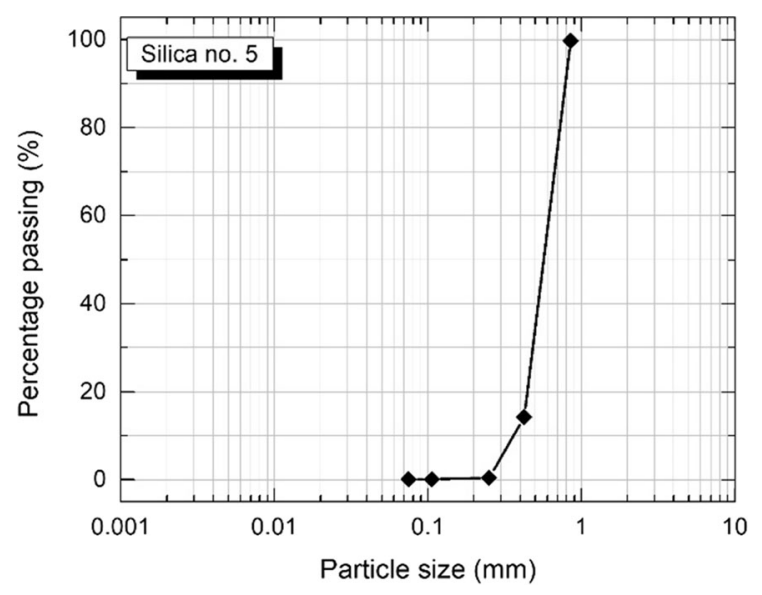

Fig. 4 Particle size distribution curve of silica sand no. 5 hopper. Similar steps were repeated until the desired height of the model ground was reached. This procedure created sand layers with a relative density of $47-50 \%$. Lastly, the pavement was placed on top of the model ground and the sand was evenly distributed to the right and left side of the pavement up to its thickness. The width, thickness, and confining pressure exerted by each pavement is provided in Table 3 .

Figure 5 shows a model view of the laminar soil box with measurement sensors. Nine accelerometers i-e A1-A9, six pore water pressure gauges (PW2, PW3, PW4, PW6, PW8, and PWP9) and two laser sensors (LS1 \& LS2) were used to monitor the acceleration response, excess pore water pressure, and settlement histories during and after the shaking. The accelerometers reading was corrected by linear base corrections and then filtered by the Butterworth filter between the frequency of $3 \mathrm{~Hz}$ and $25 \mathrm{~Hz}$ by keeping the actual nature of the response unchanged. Baseline correction was achieved by seismo signal through the leastsquare fit method (regression analysis) with the polynomial curve that best fits the time acceleration 


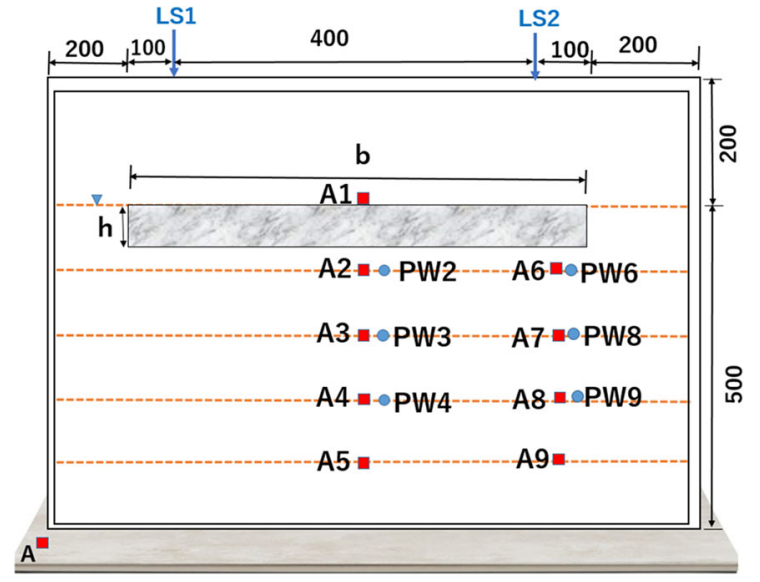

Fig. 5 Model laminar box, soil layers, and sensors measurement points

values. The filtering was performed to remove the unnecessary frequency components from the signal to smoothen the data.

Each model was subjected to a sinusoidal base acceleration motion at a frequency of $10 \mathrm{~Hz}$. The base acceleration amplitude was kept constant at about 320 gal (when a steady state of the acceleration amplitude was reached), as shown in Fig. 6.

\section{Results and Discussion}

\subsection{Effect of Thickness on Settlement and Excess Pore Pressure Development}

Figure 7 shows the average settlement-time histories for three shaking table tests Case 1, 2, and 3. The

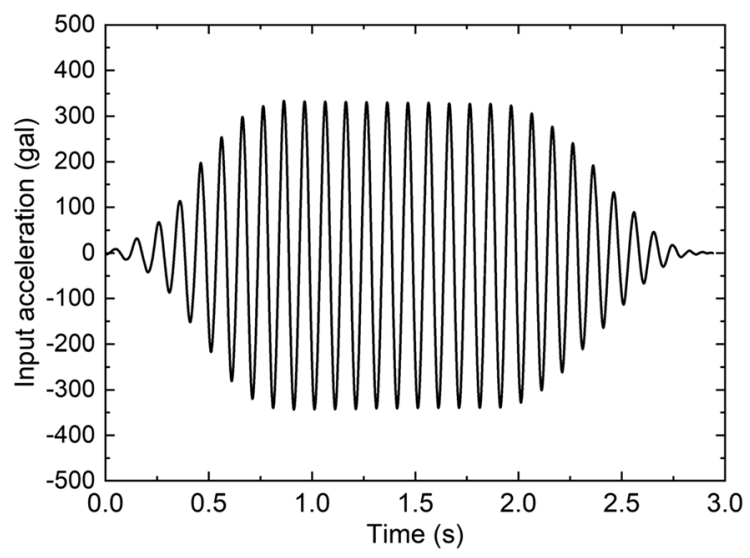

Fig. 6 Seismic loading measured at A (base of soil box)

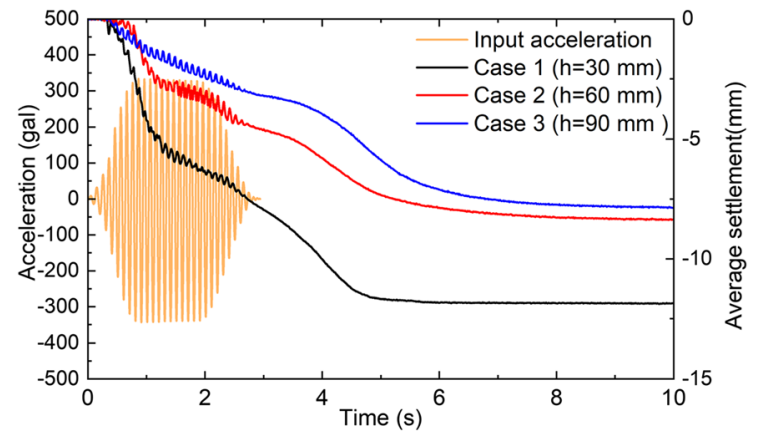

Fig. 7 Effect of pavement thickness on settlement response during shaking (width, $b=600 \mathrm{~mm}$ )

thickness of the pavement for Cases 1, 2, and 3 were 30,60 , and $90 \mathrm{~mm}$ respectively and the width was $600 \mathrm{~mm}$. All the Cases were subjected to a base acceleration of $320 \mathrm{gal}$ for $3 \mathrm{~s}$. The average settlement in the pavement was computed from the recorded data by two laser sensors (LS1 and LS2) pointed $100 \mathrm{~mm}$ at the edge of a pavement. From Fig. 6, for the first few cycles of the shaking, no noticeable settlement in the three pavements. After a few loading cycles, the pavements simultaneously started to exhibit settlement. For Case 1, an abrupt settlement in the pavement of about $5 \mathrm{~mm}$ occurred during the first $1 \mathrm{~s}$ of the shaking and for Case 2, the corresponding settlement was $2.5 \mathrm{~mm}$. The settlement in the pavements continued to develop at a reduced rate even after the termination of the shaking.

Figure $8 \mathrm{a}$ and $8 \mathrm{~b}$ show the comparison of excess pore water pressure (EPWP) time histories for Case 1 and 3 beneath and at the edge of the pavement at location A2 and A6, respectively. It can be observed from Fig. 8a, the EPWP for Case 1 is higher compared to Case 3 at the center of the pavement. Fig. $8 \mathrm{~b}$ shows a similar trend at the edge of the pavement i.e. thinner pavement developed higher EPWP. Figure 8 suggests that the thicker pavement suppressed the buildup of EPWP. This can be associated with the confining stress exerted by a pavement, i.e. a pressure of $0.63 \mathrm{kPa}$ and $1.89 \mathrm{kPa}$ of Case 1 and 3, respectively at its base.

Figure 9 shows the relationship between the settlement and EPWP against time for Case 1. From Fig. 9, it can be observed that a fast increase in the settlement rate has resulted from the rapid build-up of EPWP. The subsoil beneath the pavement liquefied, and the pavement load contributed to the settlement. 


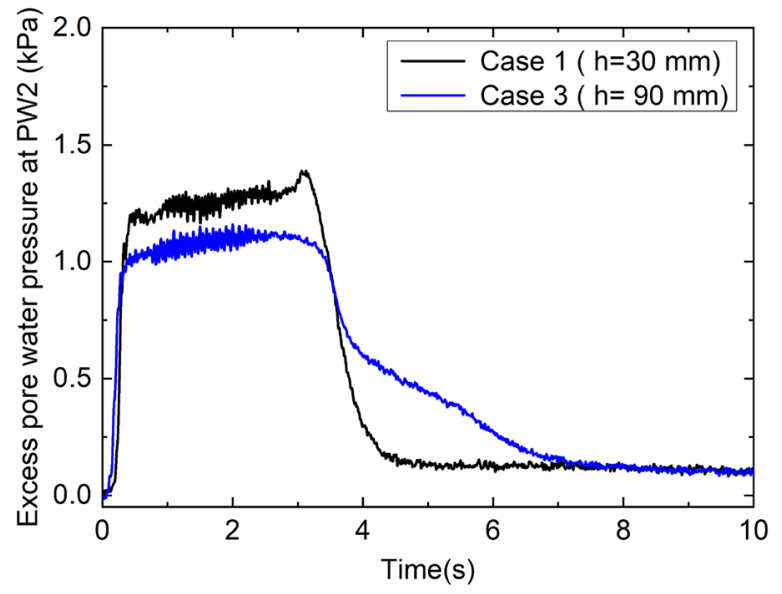

(a)

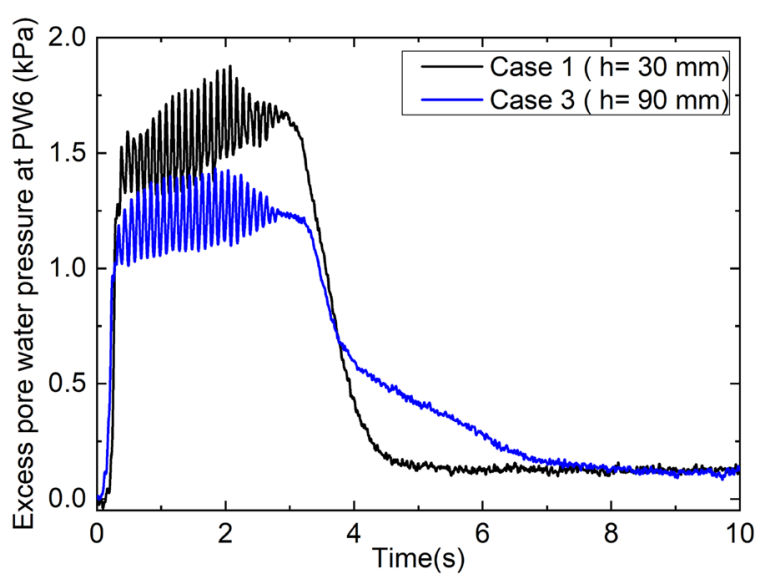

(b)

Fig. 8 Excess pore water pressure comparison of Case 1 and Case 3 a Center (PW2) b Edge (PW6)

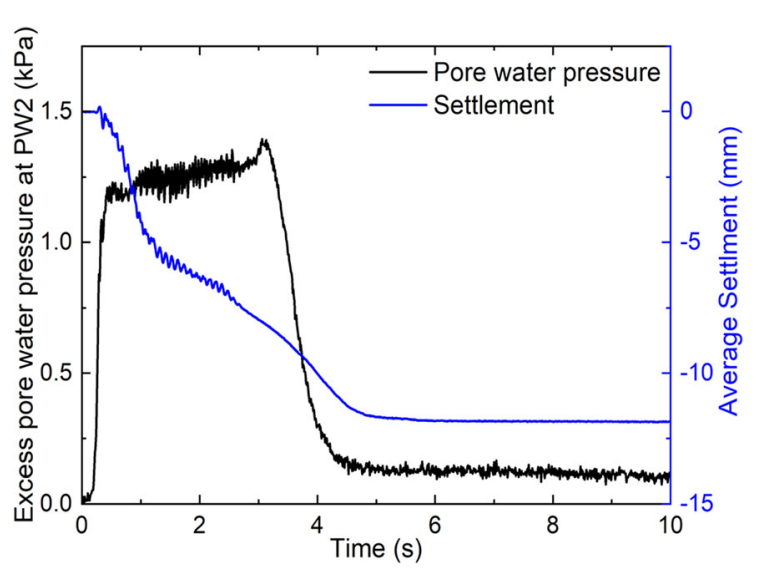

Fig. 9 Settlement and excess pore water pressure time history comparison for Case 1

The settlement time history response in Fig. 7 suggests that the total settlement can be divided into two distinguished phases, (i) co-seismic settlement: part of the total occurred during the seismic loading and (ii) post-seismic settlement: part of the total settlement occurred after the shaking. The total settlement decreased by increasing the pavement thickness, and the same trend was observed for the co-seismic settlement. The post-seismic settlement increases as the thickness of the pavement model increases (Fig. 10).

The comparison of the co-seismic and total settlement indicates that the large portion of the settlement occurred during shaking. This may be linked to the large volumetric deformation due to the partial

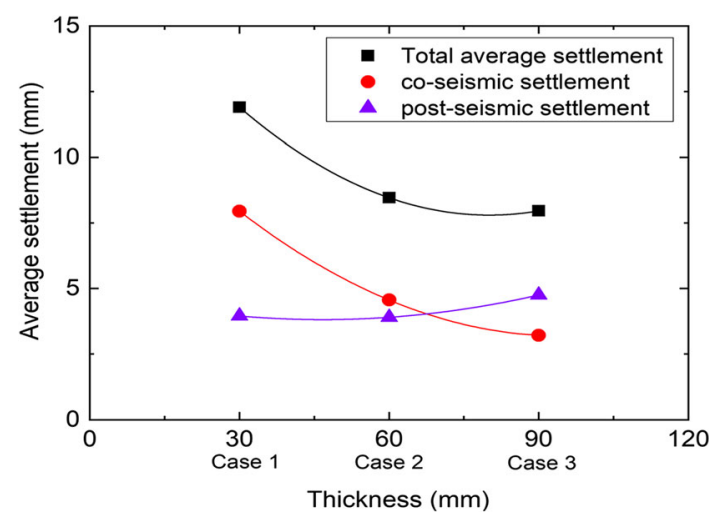

Fig. 10 Relationship between pavement thickness and settlement

drainage of the underlying soil. This observation is similar to the one reported by Meharzad et al. (2018) by conducting two rigid foundations on the surface of liquefiable soil in a centrifuge test.

The increase in the post-seismic settlement with the increase in pavement thickness would be associated with the decrease in stiffness due to the migration of water towards the pavement. A rapid EPWP dissipation occurred through the cracks observed in Case 1 and consequently resulted in less post-seismic settlements. No cracks were observed in Case 2 and Case 3; therefore, the pore water has to travel to the edges of the pavement, thus allowing the pavement to settle more in the softened underlying sand.

Experimental observations in the present study are consistent with the field observation reported by 
Konagai (2011) and Kajihara et al. (2015) following the Tohoku earthquake 2011 i.e. thinner pavement experienced higher subsidence compared to a thicker one. Previous studies by Rollins and Seed (1990) and Varghese and Latha (2013) also reported similar findings that the resistance against the pore water pressure under a shallow building could increase due to a reduction in the liquefiable layer and an increase in the effective stress by the overlying structure. Also, the cyclic resistance against pore water pressure of sand increases with increasing amplitude of initial static shear. It can be interpreted as the sub-soil will exhibit a stiffer response by increasing the overlying load on the soil and subsequently affecting the extent of deformation (Yang and Sze 2011).

\subsection{Effect of Width}

Pavements with a width of $600 \mathrm{~mm}$ (Case 2) and $300 \mathrm{~mm}$ (Case 4) and a thickness of $60 \mathrm{~mm}$ were prepared to investigate the effect of width on liquefaction-induced settlements. Case 2 represents the structure type main road, and case 4 represents the residential road of lesser width. For Case 2 and 4, the pressure exerted by the pavement at its base is $1.26 \mathrm{kPa}$ and the input acceleration of 320 gal was applied for $3 \mathrm{~s}$.

Figure 11 shows the settlement time history for Case 2 and 4 during and after the shaking. The changes in the EPWP during and after the shaking is shown in Fig. 12. Two observations can be made from Fig. 12. Firstly, the rate of settlement in Case 2 is slower compared to Case 4. Secondly, the total settlement reaches to $7 \mathrm{~mm}$ in Case 2 and $12.5 \mathrm{~mm}$ in Case 4 .

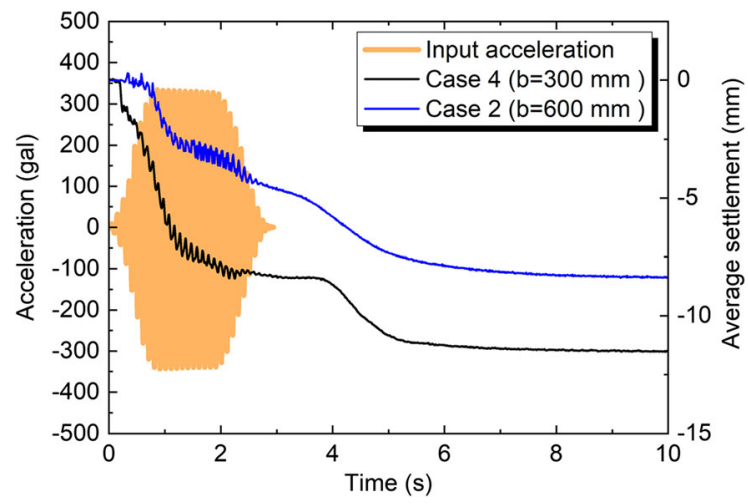

Fig. 11 Effect of pavement width on settlement response

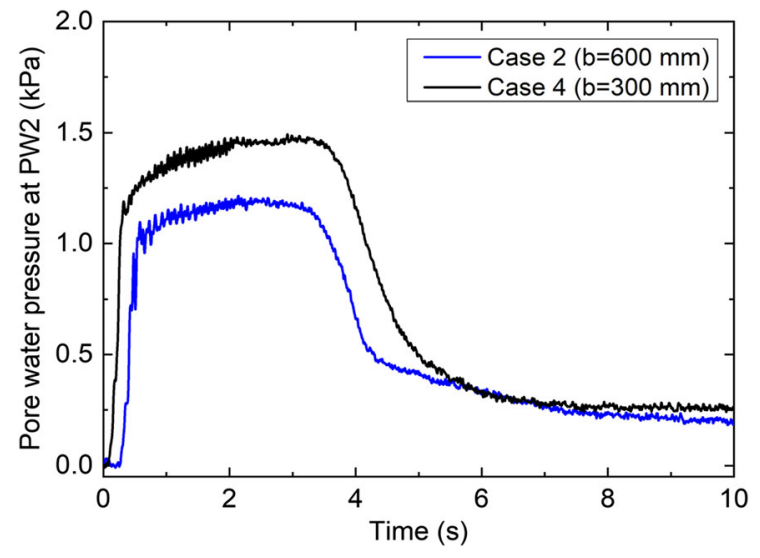

Fig. 12 Comparison of excess pore water pressure of Case 2 and Case 4 at PW2

This implies that the wider the pavement is, the lower the settlement rate and consequently, the total settlement. In addition, the absolute peak value of EPWP for Case 2 is $1.1 \mathrm{kPa}$ and Case 4 is $1.4 \mathrm{kPa}$, respectively. The comparison in Fig. 12 shows that the wider pavement suppressed the development of EPWP.

Figure 13 shows the relationship between the width of the pavement and the individual components of the settlements, co-seismic, and post-seismic settlements. It can be observed that the maximum total settlement and co-seismic settlement decreased with an increase in the width of the pavement. In addition, the postseismic settlement increases as the width of the pavement increases.

The wider pavement experiencing lesser settlement can be associated with the distribution of the pavement load over a wider area resulting in smaller shear stress

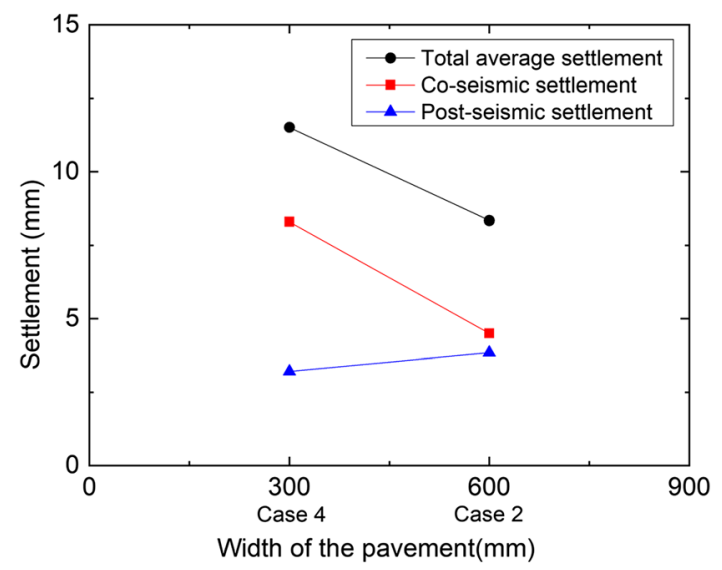

Fig.13 Relationship between pavement width and settlement 
in the soil. Also, the confining stress in the underlying soil increases as the width of the pavement increases. It is well established that higher confining stress increases the liquefaction resistance of soils. These findings are consistent with Yoshimini and Takamatsu (1977), Hatanaka et al. (1987), and Zhang and Chen (2018). These observations are also in agreement with the field subsidence data collected by Konagai (2011) following the Tohoku earthquake 2011. This provides strong experimental evidence that the subsidence map prepared by Kajihara et al. (2020) suggesting that the wider pavement can be used as an emergency evacuation route in case of future earthquakes.

\subsection{Effect of Sand Ejecta on Total Settlement}

The mechanism of liquefaction-induced settlements was well explained by Dashti et al. (2010). The total settlement after liquefaction is the combination of shear-induced deformation, volume contraction-induced deformation, and soil loss due to the ejecta. In the element and centrifuge tests, it is difficult to produce the sand ejecta due to the high confining pressure. Hence the contribution of the sand ejecta in the total settlement is still missing in the literature.

In the present study, the phenomenon of sand ejecta was successfully produced and its contribution to the settlement is determined. Before the shaking, the ground surface was horizontally leveled. The colored red sand was distributed left and ride side of the pavement model to locate the sand ejecta traces (Figs. 14 and 15). After the shaking, the sand ejecta was carefully traced, collected, and weighted. The sand ejecta contribution in the total settlement is back

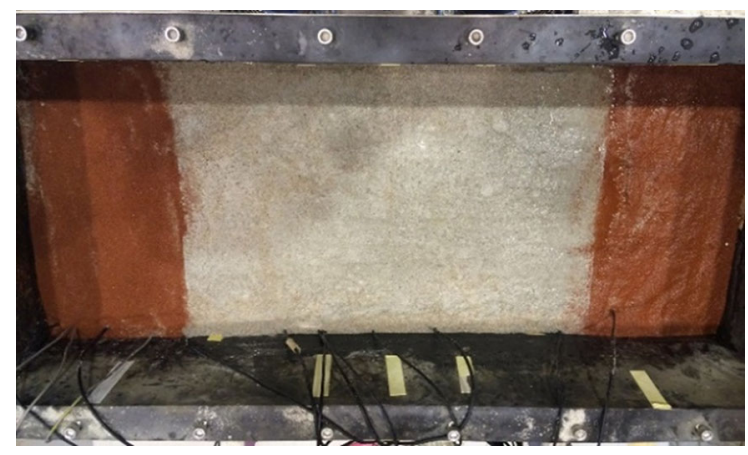

Fig. 14 Plan view of the model ground before shaking (Case 2)

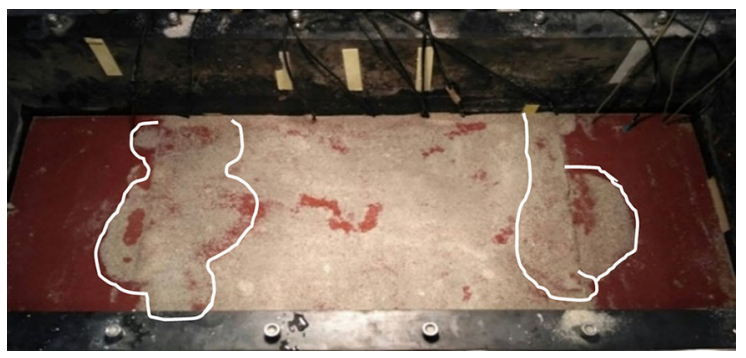

Fig. 15 Plan view of the model ground after shaking with traces of sand boiling (Case 2)

calculated and found to be around $7.7 \%$ in the total settlement for Case 2.

\section{Conclusions}

A series of 1-g shaking table model tests were conducted in laminar soil box to study the effect of thickness and width of pavement on total settlements, co-seismic settlements and post-seismic settlements. Sand ejecta contribution to the total settlement is also calculated by collecting the boiled sand after the test. Major findings of this study are as follow:

(1) The total average settlement is more for thinner pavement compared to a thicker one. The increase in the pavement thickness resulted in a reduction in the liquefiable layer and an increase in the confining stress of underlying soil.

(2) The settlement pattern can be divided into two phases: (1) the settlement occurred during shaking, co-seismic settlement (2) settlement during the reconsolidation phase, post-seismic settlements.

(3) Post-seismic settlement is lesser for the thinner pavement. This is due to the rapid pore water pressure dissipation through the cracks in the thinner pavement.

(4) Total average settlement and co-seismic settlement is lesser for wider pavement. The distribution of the structural load on the wider areas leads the smaller shear stresses in the subsoil. This smaller shear stress could have lead to the smaller lateral flow and hence the smaller settlements. 
(5) Post seismic settlement is more for the wider pavement. This is due to the slow pore water pressure dissipation in the wider pavements.

(6) The sand ejecta was observed in the model testing and its contributed to total settlement was around $7.7 \%$ of the total settlement.

\section{Declarations}

Conflict of interest The authors declare that they have no conflict of interest that could influence the work reported in this paper.

Open Access This article is licensed under a Creative Commons Attribution 4.0 International License, which permits use, sharing, adaptation, distribution and reproduction in any medium or format, as long as you give appropriate credit to the original author(s) and the source, provide a link to the Creative Commons licence, and indicate if changes were made. The images or other third party material in this article are included in the article's Creative Commons licence, unless indicated otherwise in a credit line to the material. If material is not included in the article's Creative Commons licence and your intended use is not permitted by statutory regulation or exceeds the permitted use, you will need to obtain permission directly from the copyright holder. To view a copy of this licence, visit http://creativecommons.org/licenses/by/4.0/.

\section{References}

Bray JD, Macedo J (2017) 6th Ishihara lecture: Simplified procedure for estimating liquefaction-induced building settlement. Soil Dyn Earthq Eng 102(2017):215-231

Dashti S, Bray JD, Pestana J, Riemer M, Wilson D (2010) Centrifuge testing to evaluate and mitigate liquefactioninduced building settlement mechanisms. J Geotech Geoenviron Eng 136:918-929

Hatanaka M, Suzuki Y, Miyaki M, Tsukuni S (1987) Some factors affecting the settlement of structures due to sand liquefaction in shaking table tests. Soils Found 27(1):94-101

Iai S (1989) Similitude for shaking table tests on soil-structurefluid model in $1 \mathrm{~g}$ gravitational field. Soils Found 29(1):105-118

Kajihara K, Pokhrel RM, Kiyota T, Konagai K (2015) Liquefaction-induced ground subsidence extracted from digital surface models and its application to hazard map of Urayasu City Japan. Jpn Geotech Soc Spec Publ 2(22):829-834

Kajihara K, Okuda H, Kiyota T, Konagai K (2020) Mapping of liquefaction risk on road network based on the relationship between liquefaction potential and road subsidence, Soils and Foundations: In press

Kheradi H, Nagano K, Nishi H, Zhang F (2018) 1-g shaking table tests on seismic enhancement of existing box culvert with partial ground-improvement method and its 2D dynamic simulation. Soils Found 58:563-581

Konagai, K. (2011). Map of soil subsidence in Urayasu, Chiba, caused by the March 11th, 2011 East-Japan Earthquake. Bulletin of ERS, IIS

Konagai K, Kiyota T, Suyama S, Asakura T, Shibuya K, Eto C (2013) Maps of soil subsidence for Tokyo bay shore areas liquefied in the March 11th, 2011 off the Pacific Coast of Tohoku Earthquake. Soil Dyn Earthq Eng 53:240-253

Mehrzad B, Jafarian Y, Lee CJ, Haddad AH (2018) Centrifuge study into the effect of liquefaction extent on permanent settlement and seismic response of shallow foundations. Soils Found 58(1):228-240

Miles S, Still J, Stringer M (2018) Investigating the effects of layering on the formation of sand boils in $1 \mathrm{~g}$ shaking table tests. In: McNamara A, Divall S, Goodey R, Taylor N, Stallebrass S, Panchal J (eds) Physical modelling in geotechnics. Taylor \& Francis, London, pp 999-1004

Mohsan M, Kiyota T, Munoz H, Nihaaj M and Katagiri T (2018) Fabrication and performance of laminar soil box with rigid soil box for liquefaction study Bulletin of Earthquake Resistant Structure Research Center, IIS, vol 51, University of Tokyo

Motamed R, Sesov V, Towhata I, Anh NT (2010) Experimental modeling of large pile groups in sloping ground subjected to liquefaction-induced lateral flow: 1-g shaking table tests. Soils Found 50:261-279

Rasouli R, Hayashida T, Towhata I (2012) Experimental study on subsidence of surface structures due to liquefaction and its mitigation, Proc. of 1st International symposium on earthquake engineering, Tokyo, Japan, 8-10 November 2012.

Rollins KM, Seed HB (1990) Influence of buildings on potential liquefaction damage. J Geotech Eng 116(2):165-185

Suyama S, Kiyota T, Konagai K, Kyokawa H, Uemura K, Hamanaka R (2016) Identification of factors affecting liquefaction-induced road subsidence in Urayasu City extracted from digital surface models. J JSCE C 72(1):38-47 (Japanese)

Van Laak PA, Taboada VM, Dobry R, Elgamal AW (1994) Earthquake centrifuge modelling using a laminar box. In: Ebelhar RJ, Drnevich VP, Kutter BL (eds) Dynamic geotechnical testing II, ASTMSTP1213. ASTMInternational, Pennsylvania, pp 370-384

Varghese RM, Madhavi Latha G (2013) Effect of overburden stress and surcharge pressure on the liquefaction response of sands. Int J Geotech Eng 7(4):402-410

Yang J, Sze HY (2011) Cyclic behaviour and resistance of saturated sand under non-symmetrical loading conditions. Géotechnique 61(1):59-73

Yoshimini Y, Tokimatsu K (1977) Settlement of buildings on saturated sand during eathquakes. Soils Found 17(1):23-38

Zhang J, Chen Y (2018) Experimental study on mitigations of seismic settlement and tilting of structures by adopting improved soil slab and soil mixingwalls. Sustanibility 10:4069. https://doi.org/10.3390/su10114069

Publisher's Note Springer Nature remains neutral with regard to jurisdictional claims in published maps and institutional affiliations. 